\title{
苯乙烯一反丁烯二腈光照下共聚合研究 ${ }^{*}$
}

\author{
李 橦 周春林 戴龙军 \\ (复旦大学材料科学系, 上海)
}

\section{关链词光聚合、电荷转移复合物、反丁烯二腈}

许多电子给体-受体单体组成的体系可以形成电荷转移复合物 (CTC), 从而自发地进行 热聚合,生成交替共聚物 ${ }^{(1,2)}$, 这类聚合无论从理论上还是应用上都引起了广的兴趣. 但是, 对这类体系光照下的共聚合还报道很少, 所报道的体系中一般都以马来酸酐 (MAn) 为电子 受体单体, 其中以 MAn- 苯乙烯 (St) 体系研究较多 ${ }^{[3,4]}$. 本文用受是子能力比 MAn 弱的反 丁烯二腈 (FN) 为电子受体单体, 研究其在光照下与 St 共聚合.

\section{一、实 验部 分}

1. 试剂 $F N$ ，按文献(5)合成。苯乙烯用前在 $N_{2}$ 下减压蒸馏。其它试剂均经减压蒸 馏或重结晶处理.

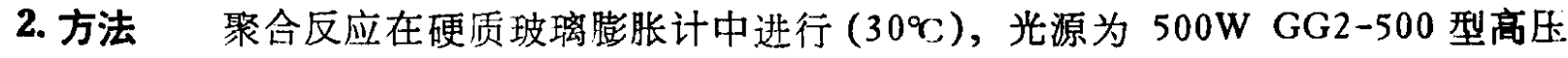
采灯. 用硫酸酮水溶液 $\left(\mathrm{CuSO} \cdot 5 \mathrm{H}_{2} \mathrm{O} 250 \mathrm{~g} / 11 \mathrm{H}_{2} \mathrm{O}, 1 \mathrm{~cm}\right.$ ) 滤去 $365 \mathrm{~nm}$ 以前的光 ${ }^{[6]}$.

电子吸收光谱和苂光光诸分别由岛津 UV-250 型分光光度计和日立 MPF-4 型荻光光 谱仪测定. ESR 谱由 ER-200D/SRC 顺磁仪测定. 将样品配成苯溶液, 取 $0.3 \mathrm{ml}$ 注人 ESR 管,通常纯氮 $3 \mathrm{~min}$ 后用 $365 \mathrm{~nm}$ 光照射一定时间,记录 ESR 图.

\section{二、结果与讨论}

1. 电子吸收光谱、苂光光谱与光聚合 图 1 示出苯乙烯 (St) 与几种腈基乙烯类电子 受体相互作用的电子吸收光谱. 弱的电子受体丙烯腈 (AN) 加人到苯乙烯中时, 没有看到吸 收光谱的变化, 表明没有检测到它们之间的基态电荷转移作用. 较强的电子受体 FN 使 St 吸收光谱向长波长方向加宽. 四腈基乙烯 (TCNE) 是极强的电子受体, 它与 St 相互作用在 长波长处产生了 $\mathrm{CTC}$ 新吸收峰.

当用 $295 \mathrm{~nm}$ 的光激发 $\mathrm{St}$ 时, 其荻光因加入 AN 而淬灭,表明 St 可以和弱的受体 AN 发 生激发态电荷转移,形成激基复合物. 图 2 示出 AN 淬灭 St 苂光的 Stern-Volmer 图. FN 淬灭St苂光要强烈得多, 其 Stern-Volmer 图向上弯曲, 意味着存在有“静态淬灭”, 即生成基态 CTC 引起的淬灭.

在暗处 St-FN 体系加热到 $50^{\circ} \mathrm{C}$ 并无聚合发生, 而用 $365 \mathrm{~nm}$ 光照时, 聚合可以进行, 并 不需任何引发剂. 由于只有二者的 CTC 在这一波长有吸收, 聚合一定是这个 CTC 吸收光

本文 1987 年 11 月 8 日收到. 1988 年 2 月15日收到供改稿.

- 公且大学科学基金资助课题。 


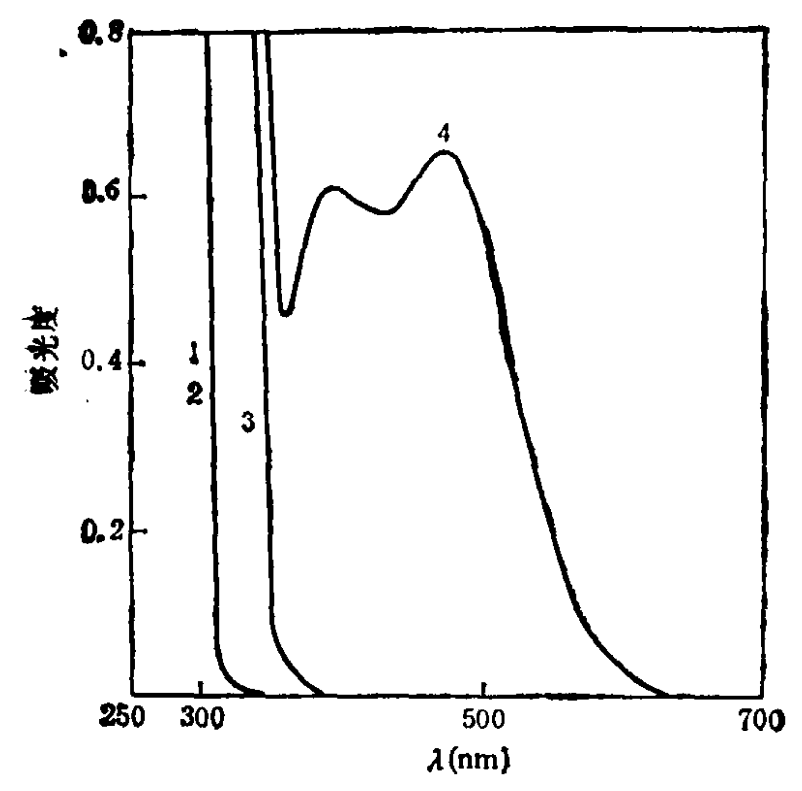

图 1 St 与腈基乙烯类化合物相互作用的电子 吸收光谱(溶剂 $\mathrm{CH}_{2} \mathrm{Cl}_{2}$ )

t. $[\mathrm{St}]=0.87 \mathrm{~mol} / 1, \mathrm{CH}_{2} \mathrm{Cl}_{2}$ 中; $2 .[\mathrm{St}]=0.87 \mathrm{~mol} / 1$,

$A N$ 中; 3. $[\mathrm{St}]=0.87 \mathrm{~mol} / 1,[\mathrm{FN}]=0.1 \mathrm{~mol} / \mathrm{l}$;

4. $[\mathrm{St}]=0.87 \mathrm{~mol} / 1,[\mathrm{TCNE}]=2 \times 10^{-3} \mathrm{~mol} / 1$

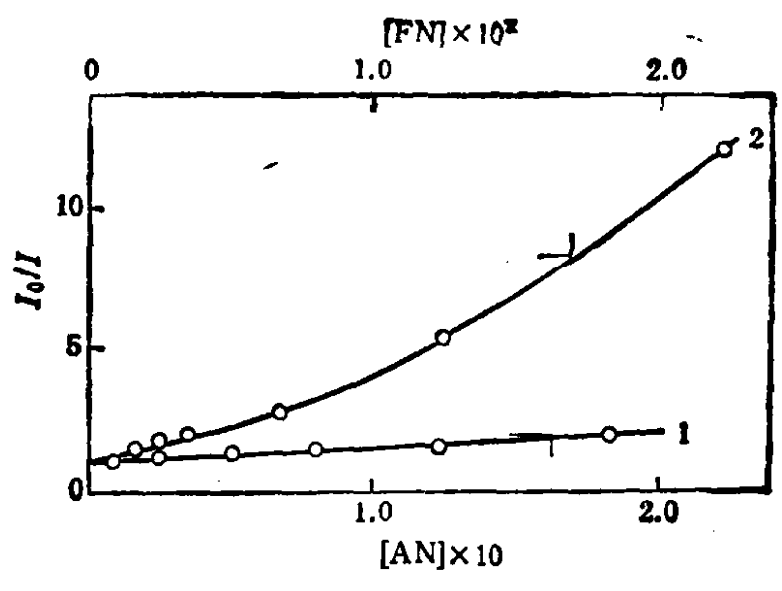

图 2 AN 和 FN 淬灭 St 苂光的 Stern-Volmer 图

1. St-AN; 2. St-FN

䜤发而引起的. St-TCNE 体系在 $365 \mathrm{~nm}$ 光照下也可聚合。而 St-AN 体系在 $365 \mathrm{~nm}$ 没有 光吸收,在我们实验条件下没有得到聚合物。

当 St-FN 聚合体系加入自由基捕捉剂 2,2,6,6-四甲基哌啶醇氮氧自由基时,光照 $2 \mathrm{~h}$ 不 聚合. 聚合前体系需通 $\mathrm{N}_{2}$ 除 $\mathrm{O}_{2}$ 否则诱导期大大延长, 聚合速度降低。这些结果都表明等合 按自由基机理进行。

2. 聚合夤度与单体浓度的关系固定 St 浓度测定聚合速度 $R$ ，与 [FN] 的关系，得 到 FN 的指数为 1.4. 如果两个单体浓度都改变, 测得 $R_{p}$ 与总浓度的指数关系是 3.0 (图 3).

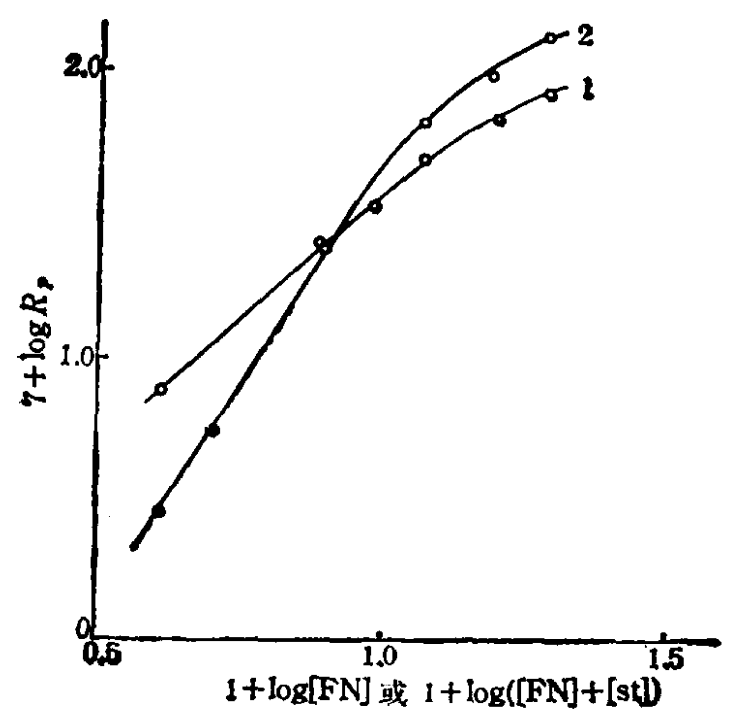

图 3 聚合速度与单体浓度关系

1. $\log R_{\mathrm{p}} \sim \log [\mathrm{FN}]([\mathrm{St}]=2 \mathrm{~mol} / 1)$;

2. $\log R, \sim \log ([\mathrm{St}]+[\mathrm{FN}])$

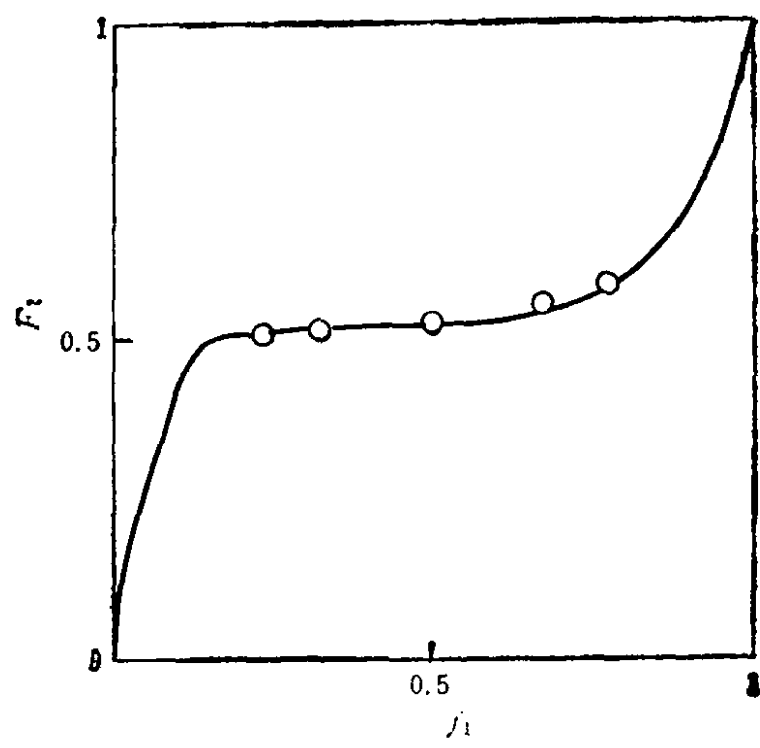

图4 $\operatorname{St}\left(M_{1}\right)-\mathrm{FN}\left(M_{2}\right)$ 体系共聚物组成曲线 
这个结果符合于两个单体都参加了引发过程和增长过程.

当单体浓度较高时, 指数有所下降(图 3). 这是体系吸光度 $8[S] l(8 、[S]$ 和 $l$ 分别为消 光系数、吸收光物质浓度和光程变高造成的, 与我们以前研究结果一致 ${ }^{[0]}$.

3. 共聚物组成曲线 图 4 是 $\mathrm{St}\left(\mathrm{M}_{1}\right)-\mathrm{FN}\left(\mathrm{M}_{2}\right)$ 体系共聚物组成曲线（共聚物组成经 元素分析测定), 求出 $r_{1}=0.2 \pm 0.02, r_{2}=0$, 表明进行的接近于交替共聚合, St 和 FN 的 CTC 不仅参加了引发过程, 而且在链增长中也起主要作用. 和 MAn-St 体系相比, FN-St 形 成基态 CTC 的能力较弱, 除 CTC 外可能有少量自由 St 分子参加共聚,这可能是 $r_{1}$ 稍大 于 0 的原因.

4. ESR 漕 用自旋捕捉剂亚硝基叔丁烷（MNP）与 ESR 相结合的方法, 我们研究<smiles>CCC(CC)N(O)C(C)(C)C</smiles>

(1)<smiles>CC(C#N)C(C#N)N(O)C(C)(C)C</smiles>

(II)

$$
\begin{aligned}
& a_{\mathrm{N}}=14.2 \mathrm{G}=14.2 \times 10^{-4} \mathrm{~T} \\
& a_{\mathrm{H}}=1.2 \mathrm{G}=1.2 \times 10^{-6} \mathrm{~T}
\end{aligned}
$$

了 St-FN 光聚合体系中生长链自由基, 得到的 ESR 谱如图 5 所示. 谱图由两组信号组成, 认 为分别归属于下列两种自由基.

其中(I)的裂分常数值与文献一致. ESR 图表 明体系中存在着 St 在末端的和 $\mathrm{FN}$ 在末端的 两种自由基,即
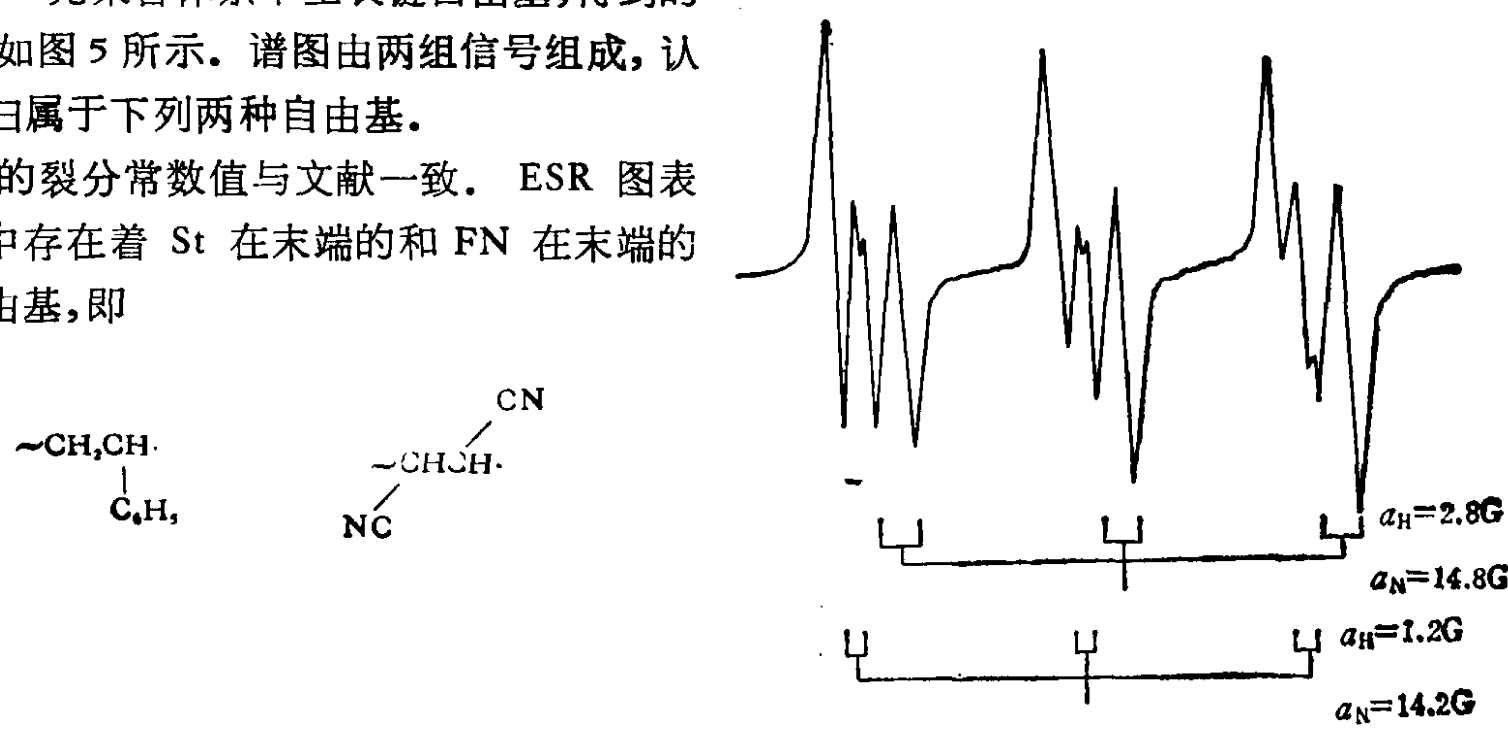

图 5 Si-FN-MNP 体系光照 $10 \mathrm{~min}$ 后 ESR 图

\section{参考文献}

[1] H.11, H. K., Jr. Angew. Chem. Int. Ea. Engl., 22(1983), 440-455.

[2]曹维毒,化学通报, 1984, 1:1-6.

[ 3 ] Barton, J., Capek, I., Arnold, M., Ratzsch, M., Makromol. Chem., 191 (1980), 241-253.

[4] Ottenbrite, R.M., Jones, J., Polymer Preprint, 26(1985), 128-129.

[5] Organic Syntheses, 30, 46-48.

[6]李棤、曹维孝、冯新德,高分子通讯, 1983,4:260-265.

[7]本栱、音维孝、冯新德,中国科学, B 辑, 1987, 5:457-462. 